\title{
BODY SIZE REGULATION IN COPEPOD CRUSTACEANS
}

BU-1463-M

November, 1999

\author{
S. Twombly ${ }^{1}$ and Nancy Tisch $^{2}$ \\ University of Rhode Island \\ Department of Biological Sciences \\ 100 Flagg Road \\ Kingston, RI 02881
}

\begin{abstract}
Body size affects survival probabilities, reproductive output and individual fitness in many organisms. In freshwater zooplankton, traits ranging from demographic rates to community composition depend on body size, and predation is most often identified as the selection pressure determining body size. We examined the extent to which stage-specific growth trajectories and body sizes of copepod crustaceans are constrained, independent of selection. We used exuviae shed at each molt to quantify the relationship between size at molting and growth during the subsequent instar for two common, herbivorous calanoid copepods, Boeckella triarticulata and Diaptomus leptopus. Individuals of both species were raised under diets of different food quality or quantity, and at different temperatures. Size at molting varied little among individuals of both species, as a consequence of a persistent negative relationship between size at molting and subsequent (absolute) growth increment. Individuals that were small when they molted grew more during the subsequent instar than individuals that were large. This relationship was statistically significant for nearly all instars of both species raised in different food or temperature conditions, and not affected by food quality, food quantity or temperature. Our results indicate that body size is constrained or regulated over much of the copepod life cycle, independent of the effects of environmental conditions (food, temperature, predation).
\end{abstract}

Keywords: body size, size regulation, copepod crustaceans, growth and development, molt increment.

To be published in Oecologia.

\footnotetext{
${ }^{1}$ To whom correspondence should be sent at above address, or to PLB101@uiracc.uri.edu. ${ }^{2}$ Current address: Department of Biometrics, 421 Warren Hall, Cornell University, Ithaca, NY, 14853
} 
. 
Body size regulation in copepod crustaceans

\author{
S. Twombly ${ }^{1}$ and N. Tisch \\ Department of Biological Sciences \\ University of Rhode Island \\ Kingston, Rhode Island 02881 USA
}

1 To whom correspondence should be addressed: Department of Biological Sciences, University
of Rhode Island, 100 Flagg Road, Kingston, R.I. 02881 USA, e-mail: PLB101@uiracc.uri.edu
${ }^{2}$ Current address: 421 Warren Hall, Biometrics Unit, Cornell University, Ithaca, N.Y. 14850 USA 


\section{Abstract}

Body size affects survival probabilities, reproductive output and individual fitness in many organisms. In freshwater zooplankton, traits ranging from demographic rates to community composition depend on body size, and predation is most often identified as the selection pressure determining body size. We examined the extent to which stage-specific growth trajectories and body sizes of copepod crustaceans are constrained, independent of selection. We used exuviae shed at each molt to quantify the relationship between size at molting and growth during the subsequent instar for two common, herbivorous calanoid copepods, Boeckella triarticulata and Diaptomus leptopus. Individuals of both species were raised under diets of different food quality or quantity, and at different temperatures. Size at molting varied little among individuals of both species, as a consequence of a persistent negative relationship between size at molting and subsequent (absolute) growth increment. Individuals that were small when they molted grew more during the subsequent instar than individuals that were large. This relationship was statistically significant for nearly all instars of both species raised in different food or temperature conditions, and not affected by food quality, food quantity or temperature. Our results indicate that body size is constrained or regulated over much of the copepod life cycle, independent of the effects of environmental conditions (food, temperature, predation).

Key Words: body size, size regulation, copepod crustaceans, growth and development, molt increment 


\section{Introduction}

Body size affects survival probabilities, reproductive output and individual fitnesses of many organisms. Environmental factors including food quality and quantity, temperature, interspecific interactions and disturbance regimes influence body size, and many studies have focused on identifying the selection (environmental) pressures responsible for the size patterns observed. Ecotherms often are larger when food is abundant or high in quality (Atkinson and Sibly 1997), when temperature is lower (Sibly and Atkinson 1994; Atkinson 1994; Berrigan and Charnov 1994), or when size-selective predators prefer smaller individuals (e.g., Paine 1965; Bertness 1981; Berven and Gill 1983). Size at metamorphosis or maturity also can be affected by both food availability and predation (e.g., Collins 1979; van der Veer and Bergman 1987; Bradshaw and Johnson 1995; Smith and van Buskirk 1995). Selection acting on body size is recognized as the primary factor generating and maintaining observed patterns of variation in body size.

An implicit assumption of these life-history studies is that selection acts on completely flexible growth trajectories, and it is the consequences of body size that have attracted most attention (e.g., Peters 1983; Roff 1992; Stearns 1992). However, additional processes may affect body size. Physiological, developmental or structural constraints may limit maximum, optimum or minimum body sizes, along with variation in size at any particular point during the life cycle (e.g., Wilbur and Collins 1973; Nijhout 1975; Hartnoll and Dalley 1981). For a variety of organisms exhibiting complex life cycles, body size at metamorphosis or maturity depends on both external (environmental) and internal (physiological, structural) constraints, and models predicting either 
flexible (e.g., Wilbur and Collins 1973) or fixed (Leips and Travis 1994) body sizes are supported empirically (Reznick 1990; Hensley 1993; Leips and Travis 1994). For example, the timing of amphibian and insect metamorphosis may be fixed by the onset of the endocrine cascade that effects morphological change (e.g., Gilbert et al. 1996). Given this constraint, Hensley (1993) argued for the amphibian Pseudacris crucifer that the body size achieved at metamorphosis cannot be optimized by selection because it depends on food encountered once metamorphosis has been triggered. Arthropod body sizes are determined by the growth achieved during discrete developmental stages; and growth achieved per molt, the size at molting, or instar duration reflect structural or physiological constraints as well as direct responses to selection (Higgins and Rankin 1996). With this evidence for body size constraints, full understanding of the ecological or the evolutionary significance of body size in any particular species or population requires examination of both the selection pressures acting on body size and the constraints that limit body size.

Constraints on growth or body size, and the interdependence of growth and development, have received far less attention in many organisms, including the crustaceans we examine here, than the consequences of body size. Among crustaceans, larvae of the caridean shrimp Palaemon elegans (Hartnoll and Dalley 1981) and the barnacle Balanus eburneus (West and Costlow 1987) accomplish size regulation by a negative feedback between molt increment and premolt size: individuals that are large at a particular larval molt accomplish a small growth increment during the next molt and vice versa. This relationship suggests the ability to modify growth rates based on previous growth history such that body size at molting varies little among individuals in any particular stage. 
Since Brooks and Dodson (1965) proposed the Size-Efficiency Hypothesis, body size has played a major role in studies of the ecology and evolution of freshwater zooplankton. However, our understanding of the factors affecting zooplankton body size has been limited almost exclusively to environmental (selective) factors, and has focused on predation as the principal of these. Food and temperature have clear immediate effects on body size, but predation pressures are usually considered the ultimate causes of size-specific life history transitions (Lynch 1980; Hairston et al. 1983; Riessen et al. 1984; Papinska 1988; Hairston 1987), behaviors (e.g., Zaret and Suffern 1976; Neill 1990), morphology (Dodson 1974, 1989), and community composition (Carpenter et al. 1985; DeMelo et al. 1992; Strong 1992). This limitation is not purely conceptual; logistically, it has been difficult if not impossible to measure individual size nondestructively, particularly of larval copepod (naupliar) stages. This difficulty has severely limited our understanding of the range of factors affecting individual growth and body size (Thompson 1982; Hart 1990; van den Bosch and Gabriel 1994), including factors that might constrain body size.

Recent use of exuviae shed by crustacean zooplankton at each molt to measure individual size at successive stages and individual growth trajectories (Twombly and Burns 1996) provides an opportunity to examine growth dynamics and the factors affecting body size in more detail. Analyses of exuviae shed over the entire life cycle of a large number of individuals of the copepod Boeckella triarticulata revealed limited size variation at each molt (Twombly and Burns 1996a). These results suggested that copepod body size is constrained over some or much of the life cycle (see also Twombly 1993, 1995). Our purpose in the studies reported here was to identify both the 
potential mechanism of size constraint as well as the instars during which it acts for two freshwater calanoid copepod species, Boeckella triarticulata Thomson and Diaptomus leptopus Forbes. Growth dynamics throughout the life cycle, including the relationships between molt increment and size at molting or instar duration, were quantified, and the effects of diet and temperature on these relationships were measured.

\section{Materials and Methods}

Because ovigerous females of each species were collected from different field locations at different times, and their offspring were raised under different conditions (light, temperature, food), the experimental protocol used is described separately for each species.

Boeckella triarticulata: Ovigerous females were collected from Saddle Hill Quarry Pond, approximately $20 \mathrm{~km}$ west of Dunedin, New Zealand, isolated in approx. $30 \mathrm{ml}$ spring water, and kept at $15^{\circ} \mathrm{C}$ and $14: 10$ light:dark photoperiod until their eggs hatched. Eleven newborn nauplii from each of 5 sibships were reared in two different diets: 1) Cryptomonas sp. at a concentration of $0.4 \mathrm{mg}$ dry weight (DW) $\mathrm{L}^{-1}$ (henceforth referred to as $\mathrm{CR}$ ), and a combination of Cryptomonas sp. and Anabaena flos-aquae (1:1 by dry weight) at the same concentration (i.e., $0.2 \mathrm{mg} \mathrm{DW} \mathrm{L}^{-1}$ of each species, referred to as $\mathrm{C}-\mathrm{A}$ ). Nauplii were reared individually in plastic vials containing $15 \mathrm{ml}$ of a mixture (1:1) of modified MBL medium (Stemberger 1981) and spring water, at $15^{\circ} \mathrm{C}$ and $14: 10$ photoperiod. Food and medium were replaced every second day. When nauplii metamorphosed to the first copepodite stage, food concentrations were increased to 1.2 mg DW L ${ }^{-1}$; food was increased again (to $2.0 \mathrm{mg} \mathrm{DW} \mathrm{L}^{-1}$ ) when animals reached maturity. Adult 
food concentration was kept above the incipient limiting concentration for B. triarticulata (Burns and Xu 1990; Burns and Hegarty, unpublished).

Individuals were examined daily for shed exuviae using a stereomicroscope with darkfield illumination at 15-40X. Exuviae were measured at $100 \mathrm{X}$ (N1-CI) or $40 \mathrm{X}$ (CII-CV) under a compound microscope using a calibrated ocular micrometer. The lengths of entire naupliar exuviae were measured from the anterior mid-dorsal margin to the base of the caudal spines; copepodite exuviae were measured from the anterior to mid-dorsal posterior margins of the prosome. The developmental stage of each exuvium was verified at measurement.

Cryptomonas sp. stock cultures were maintained in modified MBL medium (Stemberger 1981 ) at $20^{\circ} \mathrm{C}$ in dim light at $12: 12$ light:dark cycle; $A$. flos-aquae cultures were grown in WC medium (Guillard and Lorenzen 1972) and kept at ambient temperature and photoperiod. Algal stock concentrations were determined turbidimetrically and translated to DW/L using a previously-determined dry weight regression. Appropriate volumes of each algal stock culture were added to culture medium (modified MBL medium and spring water) to obtain the final food concentration required, depending upon individual developmental stage.

Diaptomus leptopus: Ovigerous females were collected from Little Bullhead Pond in Perryville, Rhode Island, in February and May 1998, and kept individually in the laboratory in $12 \mathrm{ml}$ modified MBL medium at near ambient field conditions (for February females, $8^{\circ} \mathrm{C}$ and 10:14 photoperiod; for June females, $16^{\circ} \mathrm{C}$ and $14: 10$ photoperiod) until their eggs hatched. Nauplii from the February females were raised individually in small petrie dishes in $12 \mathrm{ml}$ modified MBL medium at $8^{\circ} \mathrm{C}$ and 10:14 Photoperiod. Fifteen offspring from each of 5 sibships were reared on a 
combined diet (1:1 by carbon content) of Chlamydomonas reinhardtii and Cryptomonas erosa at two different concentrations, $0.6 \mu \mathrm{g} \mathrm{C} \mathrm{ml}^{-1}$ and $1.2 \mu \mathrm{g} \mathrm{C} \mathrm{ml}^{-1}$. Nauplii hatched from fieldcollected females in May were pooled and 45 individuals were reared individually, on the same combined diet and at the same food concentrations as February offspring, at $16^{\circ} \mathrm{C}$ or $19^{\circ} \mathrm{C}$ and at 14:10 photoperiod. All individuals were observed daily $\left(16^{\circ} \mathrm{C}, 19^{\circ} \mathrm{C}\right)$ or every second or third day $\left(8^{\circ} \mathrm{C}\right)$ for the presence of exuviae, and both food and medium were changed every second or third day. Exuviae were measured at 50X under a stereomicroscope using a calibrated ocular micrometer. Lengths of naupliar exoskeletons were measured from the anterior mid-dorsal margin to the base of the caudal spines, and entire copepodite exuviae were measured from the anterior mid-dorsal margin to the base of the caudal rami.

Stock cultures of both $C$. reinhardtii and C. erosa were maintained in modified MBL medium at $16-18^{\circ} \mathrm{C}$ in dim light at $12: 12$ light:dark cycle. Algal stock concentrations were determined using a hemacytometer and translated to $\mu \mathrm{g} \mathrm{Cml}^{-1}$ using equations reported by Strathmann (1967). Appropriate volumes of each algal stock culture were added to modified MBL medium to obtain the final food concentrations required.

Statistical Analyses: Means, variances, coefficients of variation and other statistical analyses described below were calculated or carried out for $7-11$ of the possible 13 developmental stages. In both species, the second naupliar (N2) molt was the first one reliably recorded in the experimental chambers (because the first, non-feeding larval instar is completed quickly), with the result that the first molt increment data that could be related to size at molting were for the third naupliar (N3) stage. We measured different exuvium dimensions for $B$. triarticulata nauplii and 
copepodites (see above) and therefore were unable to calculate an accurate molt increment for the first copepodite stage (CI). Growth statistics are reported for CII-CVI stages only. This problem was eliminated for $D$. leptopus by measuring the entire length of copepodite exuviae. Reproductive maturity is achieved at the molt from the CV to the CVI stage, when molting ceases, and a CVI molt increment was determined by measuring length of all adults at death.

We used parametric correlation analysis to examine the relationship between molt

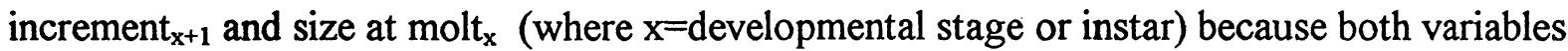
were measured with error. Analysis of covariance (ANCOVA) was performed to detect differences in this relationship due to diet (food quality or quantity) or temperature (D. leptopus only). Spearman rank correlations were used to investigate the relationship between molt increment and instar duration because instar durations were not normally distributed. Females and males were analyzed separately in the penultimate and ultimate instars, as growth trajectories diverged in later copepodite stages and males were usually smaller than females by the fifth copepodite stage. Despite this sexual dimorphism, sexes did not differ statistically in the strength of the correlation between molt increment and size at molting, or in the effects of environmental conditions on this relationship. As a result, sexes are pooled in the results presented below. All statistical tests were run using SAS version 6.08 or 6.12 (SAS Institute 1985).

\section{Results}

Growth dynamics: Size at each molt varied little among individuals raised on a given diet; coefficients of variation (C.V.) ranged from 3.5-6\% (Figure 1). Absolute molt increments (the 
change in size from one molt to the next) increased from N3 to CIV stages in both species. Stagespecific variation in molt increments was much higher (C.V. 20-35\%) than that for size at molting and was equal across all stages (Figure 1).

These highly variable molt or growth increments are not due to large differences among individuals in the amount of time spent in any particular stage (instar duration). Instar duration was not correlated with molt increment for either B. triarticulata or D. leptopus (only one of 34 correlations was significant at $\mathrm{p}<0.05$ ), so that larger molt increments were not the result of prolonged development. In fact, growth within a stage was often negatively correlated with stage duration.

Correlation analyses revealed highly significant negative relationships between molt increment and size at molting for $60-80 \%$ of the developmental stages quantified (Figures 2 and 3). This relationship was negative but not significant ( $>0.05$ ) among most older juvenile stages. As a result of individual variation in molt increment, size at each molt varied little. When individuals in successive instars overlapped in size at molting, they achieved different absolute molt increments (see Figure 2, stages N3 and N4; Stages CIII and CIV), suggesting that the relationship between molt increment and size at molting is 'reset' at each instar (West and Costlow 1987). Individuals in the younger stage were large at molting and exhibited relatively small molt increments, while equal-sized individuals in the next instar were relatively small and exhibited large molt increments.

Food quality had small but statistically significant $(\mathrm{p}<0.05)$ effects on body sizes achieved in later instars of $B$. triarticulata (Figure 1). Similarly, temperature affected body size of the last 
naupliar and all copepodite stages of $D$. leptopus ( $\mathrm{p}<0.05$ ), even though the absolute changes were small and the trends exhibited were opposite those recorded for many ectotherms. In all later copepodite stages of D. leptopus, individuals raised at $16^{\circ} \mathrm{C}$ were larger than those raised at $8^{\circ} \mathrm{C}$. Effects of diet and temperature on growth dynamics: Although food quality had a significant effect on body size and absolute molt increment in B. triarticulata (Figure 1A; Twombly and Burns 1996), and food quantity caused significant differences in body size of adult $D$. leptopus (Figure 1B, C), neither food quantity (for D. leptopus) or quality (for B. triarticulata) affected the relationship between molt increment and premolt size in either species, with the exception of the CV size-CVI increment relationship in male $B$. triarticulata (Table 1A, B nonsignificant size*diet interaction terms). Similarly, temperature did not alter the molt increment-size at molting relationship in D. leptopus (Table 1C), even though temperature had a statistically significant effect on overall body size. Constancy of the stage-specific relationship between molt increment and size at molting, regardless of these experimental conditions, lends further support to a general mechanism for size regulation. Both $B$. triarticulata and $D$. leptopus retain the ability to adjust growth rates based on body size, and thus to minimize size variation, over most developmental stages.

\section{Discussion}

\section{Body size regulation}

Body size achieved at each of several successive molts in two common calanoid copepods varied little among individuals raised in controlled laboratory conditions. Age at molting and molt 
increment were more variable than body size among these individuals, and intra-instar variation in molt increment was significantly related to size at molting over larval and the first three juvenile stages. Growth achieved within a particular instar (the molt increment) varied negatively with body size of individuals entering that instar; these data demonstrate clear constraints on body size in two copepod crustaceans. Less complete data also show the existence of the same negative relationship for naupliar and copepodite stages of two other copepods, Diaptomus sanguineus and Acartia tonsa (Twombly, unpublished). The negative relationship was weaker in older stages, perhaps because size regulation weakens when morphogenesis ceases in copepods.

Size regulation within an instar via a negative feedback mechanism has been reported in two other crustaceans, the barnacle Balanus eburneus (West and Costlow 1987) and the decapod Palaemon elegans (Hartnoll and Dalley 1981). Barnacle molt increments were negatively related to size at molting over all larval stages up to - but not including - the cyprid stage, at which point size regulation ceased. In contrast, size appeared regulated only at specific stages (metamorphosis and maturity) during the life cycle in P. elegans, and varied considerably in other instars (Hartnoll and Dalley 1981). West and Costlow (1987) concluded that the negative feedback between molt increment and size at molting in B. eburneus was reset at each molt, and the same appears to be true for both copepod species described here. For example, when successive stages of $B$. triarticulata overlapped in size at molting, the earlier instar exhibited a smaller molt increment than the later one did (see Figure 2).

Our experimental conditions - changes in food quality, food quantity, and temperature effected only small changes in copepod body sizes over the life cycle, and these changes were 
statistically significant only in older copepodite stages (including the adult). While surprising, these results are corroborated by other studies showing only small effects of food or temperature on zooplankton body size (measured as length or dry weight) and significant effects primarily on the oldest stages (e.g., Vidal 1980; Tessier and Consolatti 1991; Ban 1994), and they provide further evidence for constraints on body size. Similarly, our experimental conditions had no detectable effect on the negative relationship between molt increment and size at molting. The potential feedback exhibited appears to be independent of immediate environmental conditions. It also appears to be unrelated to at least one major exoskeletal constraint: if maximum growth per ecdysis is limited by how tightly new cuticle can be packed within the existing exoskeleton (Cheng and Chang 1994; Higgins and Rankin 1996), then larger individuals within an instar should exhibit larger molt increments.

The constraints on growth and body size that we document here suggest that body size may not be as important a fitness trait in copepods as it is in other organisms. Although larger body size results in increased reproductive output in many invertebrates (including other crustaceans), the effect of adult body size on reproductive output in several copepods is unclear (Twombly et al. 1998, unpublished data; see also Peterson et al. 1991; Hart et al. 1995). Individual lifetime fitness depends on body size in B. triarticulata, but not in D. leptopus (unpublished data). Reproductive output or effort may relate more directly to individual energy storage than to body length for invertebrates that broadcast their gametes or carry their eggs externally (e.g., Thompson 1982). In several copepods, size at specific life cycle transitions (metamorphosis, maturity) varies less than age at these transitions (Twombly 1995, 1996), and 
there is no apparent relationship between instar duration and size at molting (this study). Individuals cannot grow larger by remaining within a particular stage for a longer period of time. Finally, lower temperatures did not result in larger body sizes (at maturity, for example) in $D$. leptopus, in contrast to the response documented in many other ectotherms (Berrigan and Charnov 1994). These observations indicate that body size has different life-history consequences in copepods than those typically assumed.

\section{Interdependence of growth and development (morphogenesis)}

Growth and development are often assumed to be interdependent processes, largely because age and size at particular life-history transitions (such as metamorphosis or maturity) are positively correlated (e.g., Collins 1979; Smith-Gill and Berven 1979; Chambers et al. 1988; Mitchell-Olds 1996). Alternatively, these correlations may represent similar but independent responses of growth and development to the same ecological conditions (Leips and Travis 1994; Blanckenhorn 1998), with the result that statistical correlations between age and size at any particular life cycle transition say little about the degree to which growth and development are genetically coupled. Copepod age and size at metamorphosis or maturity are often negatively correlated (Twombly 1996; Twombly and Burns 1996); and in both B. triarticulata and D. leptopus (this study), molt increment (or growth achieved during an instar) was not correlated (significantly) with instar duration.

Copepod crustaceans have a fixed number of instars (Elgmork and Langeland 1970; Czaika 1982), and morphogenesis (the addition of segments, appendages and setae) must be 
closely coupled with molting although the relationship between these two processes has not yet been thoroughly examined. West and Costlow (1988) proposed that growth and morphogenesis were coupled in Balanus eburneus in order to maximize the probability that morphogenesis, once initiated, would be completed by the end of a particular instar. They also considered that the coupling of growth and development resulted from an equal allocation of energy to each process. In contrast, the uncoupling of growth and morphogenesis or morphogenesis and molting in decapod crustaceans has been well documented (Gore 1985). Supernumerary instars are often associated with delayed or extended development in particular environmental conditions and this flexible number of instars indicates that variable morphogenesis can be achieved with each molt (Knowlton 1975; Gore 1985; McConaugha 1985). Decapods appear to allocate energy first to maintenance, second to molting and finally to morphogenesis (McConaugha 1985).

The constraints on growth and body size described here for two copepod crustaceans may limit their ability to respond phenotypically (via plasticity) to temporal and spatial variation in habitat quality and may therefore limit their ecological success (Higgins and Rankin 1996, Blanckenhorn 1998). Other aspects of copepod life-histories are similarly constrained: Hairston and Bohonak (1998) characterized freshwater, free-living copepods as iteroparous annuals with resting stages. Despite these constraints, however, copepods are successful in spatially and temporally variable inland habitats. A more complete understanding of the evolution of copepod life-histories, and of the life-history variation maintained within the constraints mentioned above, requires quantification of the genetic bases for the various constraints that exist, their phenotypic manifestation, and both the short- (ecological) and long-term (evolutionary) consequences of life- 
history constraints in this highly successful group.

\section{Acknowledgements}

We thank Brendan O'Neill, Jackie Putier, Carey DeLauder and Heather DeWitt for collecting some of the data used in this analysis. David Brakke and two anonymous reviewers provided comments that considerably improved the manuscript. ST is grateful to Carolyn Burns and members of the Zoology Department, University of Otago, Dunedin, New Zealand, for support during a sabbatical leave, when data on $B$. triarticulata were collected. Financial support was provided by the University of Rhode Island. 


\section{Bibliography}

Atkinson D (1994) Temperature and organism size - a biological law for ectotherms? Adv. Ecol. Res. 25:1-58

Atkinson D, Sibly RM (1997) Why are organisms usually bigger in colder environments? Making sense of a life history puzzle. Trends in Ecology and Evolution 12:235-239

Ban S (1994) Effect of temperature and food concentration on post-embryonic development, egg production and adult body size of calanoid copepod Eurytemora affinis. J. Plankton Res. $16: 721-735$

Berrigan D, Charnov EL (1994) Reaction norms for age and size at maturity in response to temperature: a puzzle for life historians. Oikos 70: $474-478$

Bertness MD (1981) Pattern and plasticity in tropical hermit crab growth and reproduction. Am. Nat. 117:754-773.

Berven KA, Gill DE (1983) Interpreting geographic variation in life-history traits. Am. Zool. 23:85-97.

Blakley N, Goodner SR (1978) Size-dependent timing of metamorphosis in milkweed bugs (Oncopeltus) and its life history implications. Biol. Bull. 155: 499-510

Blanckenhorn WU (1998) Adaptive phenotypic plasticity in growth, development, and body size in the yellow dung fly. Evolution 52:1394-1407

Bradshaw WE, Johnson K (1995) Initiation of metamorphosis in the pitcher-plant mosquito: effects of larval growth history. Ecology 76:2055-2065

Brooks JL, Dodson SI (1965) Predation, body size and composition of plankton. Science 
$150: 28-35$

Burns CW, Xu Z (1990) Calanoid copepods feeding on algae and filamentous cyanobacteria: rates of ingestion, defaecation and effects on trichome length. J. Plankton Res. 12:201-213

Carpenter SR, Kitchell JF and Hodgson JR (1985) Cascading trophic interactions and lake productivity. BioScience 35:634-639

Chambers RC, Leggett WC and Brown JA (1988) Variation in and among early life history traits of laboratory-reared winter flounder Pseudopleuronectes americanus. Mar. Ecol. Prog. Ser. 47:1-15

Cheng J-H, Chang ES (1994) Determinants of postmolt size in American lobster (Homarus americanus). 2. Folding of premolt cuticle. Can. J. Fish. Aquat. Sci. 51:1771-1779.

Collins JP (1979) Intrapopulational variation in the body size at metamorphosis and timing of metamorphosis int he bullfrog Rana catesbeiana. Ecology 60:738-749

Czaika SC (1982) Identification of nauplii N1-N6 and copepodids CI-CVI of the Great Lakes calanoid and cyclopoid copepods (Calanoida, Cyclopoida, Copepoda). J. Great Lakes Res. 8:439-469

DeMelo R, France R, McQueen DJ (1992) Biomanipulation: hit or myth? Limnol. Oceanogr. 37 : 192-207

Dodson SI (1974) Adaptive change in plankton morphology in response to size-selective predation: a new hypothesis of cyclomorphosis. Limnol. Oceanogr. 19:721-729

Dodson SI (1989) Predator-induced reaction norms. BioScience 39:447-452 
Elgmork K, Langeland A (1970) The number of naupliar instars in Cyclopoida

(Copepoda). Crustaceana 18:277-282

Gilbert LI, Tata JR, Atkinson BG (eds) (1996). Metamorphosis. Postembryonic Reprogramming of Gene Expression in Amphibian and Insect Cells. Academic Press, New York

Gore RH (1985) Molting and growth in decapod larvae. In: Wenner AM (ed) Crustacean Issues

Vol. 2: Larval Growth. A.A. Balkema, New York, pp 1-65

Guillard RRL, Lorenzen CJ (1972) Yellow-green algae with chlorophyllide c. J. Phycol. 8:

$10-14$

Hairston NG,Jr (1987) Diapause as a predator-avoidance adaptation. In: Kerfoot WC, Sih A (eds) Predation: Direct and Indirect Impacts on Aquatic Communities. University Press of New England, Hanover, New Hampshire, pp 281-190

Hairston NG,Jr, Bohonak AJ (1998) Copepod reproductive strategies: life-history theory and phylogenetic pattern. Journal of Marine Systems 15:23-34

Hairston NG,Jr, Walton WE, Li KT (1983) The causes and consequences of sex-specific mortality in a freshwater copepod. Limnol. Oceanogr. 28:935-947

Hart RC (1990) Copepod post-embryonic durations: pattern, conformity, and predictability. The realities of isochronal and equiproportional development, and trends in the copepodidnaupliar duration ratio. Hydrobiologia 206:175-206

Hart RC, Irvine K, Waya R (1995) Experimental studies on food dependency of development times and reproductive effort (fecundity and egg size) of Tropodiaptomus cunningtoni in relation to its natural distribution in Lake Malawi. Arch. Fur Hydrobiologie 133:23-47 
Hartnoll RG, Dalley R (1981) The control of size variation within instars of a crustacean $J$. Exp. Mar. Biol. Ecol. 53:235-239

Hensley FR (1993) Ontogenetic loss of phenotypic plasticity of age at metamorphosis in tadpoles. Ecology 74:2405-2412

Higgins LE, Rankin MA (1996) Different pathways in arthropod postembryonic development. Evolution 50:573-582

Knowlton RE (1975) Larval developmental processes and controlling factors in decapod Crustacea, with emphasis on Caridea. Thalassia Jugosl. 10:139-158

Leips J, Travis J (1994) Metamorphic responses to changing food levels in two species of hylid frogs. Ecology 75:1345-1356

Lynch M (1980) The evolution of cladoceran life histories. Quart. Rev. Biol. 55:23-42

McConaugha JR (1985) Nutrition and larval growth. In: Wenner AM (ed) Crustacean Issues 2:

Larval Growth. A.A. Balkema, Boston, pp. 127-154

Mitchell-Olds T (1996) Genetic constraints on life-history evolution: quantitative-trait loci influencing growth and flowering in Arabidopsis thaliana. Evolution 50:140-145

Neill WE (1990) Induced vertical migration in copepods as a defence against invertebrate predation. Nature 345:524-526

Nijhout HF (1975) A threshold size for metamorphosis in the tobacco horn-worm Manduca sexta (L.). Biol. Bull. (Woods Hole) 149:214-225

Paine RT (1965) Natural history, limiting factors and energetics of the opisthobranch Navanax inermis. Ecology 46:603-619. 
Papinska K (1988) The effect of fish predation on Cyclops life cycle. Hydrobiologia 167/168: $449-453$

Peters RH (1983) The Ecological Implications of Body Size. Cambridge University Press, New York

Peterson WT, Tiselius P, Kiørboe T (1991) Copepod egg production, moulting and growth rates, and secondary production, in the Skagerrak in August 1998. J. Plankton Res. 13: $131-154$

Reznick DN (1990) Plasticity in age and size at maturity in male guppies (Poecilia reticulata): An experimental evaluation of alternative models of development. J. Evol. Biol. 3:185-203.

Riessen HP, O'Brien WJ, Loveless B (1984) An analysis of the components of Chaoborus predation on zooplankton and the calculation of relative prey vulnerabilities. Ecology 65: $514-522$

Roff DA (1992). The Evolution of Life Histories. Chapman and Hall, New York.

SAS Institute, Inc (1985) SAS User's Guide: Statistics. Fifth edition. SAS Institute, Cary, North Carolina, USA

Sibly RM, Atkinson D (1994) How rearing temperature affects optimal adult size in ectotherms. Funct. Ecol. 8:486-493

Smith-Gill SJ, Berven KA (1979) Predicting amphibian metamorphosis. Am. Nat. 113:563-585

Smith DC, VanBuskirk J (1995) Phenotypic design, plasicity, and ecological performance in two tadpole species. Am. Nat. 145:211-233

Stearns SC (1992) The Evolution of Life Histories. Oxford University Press, New York 
Stemberger RS (1981) A general approach to the culture of planktonic rotifers. Can. J. Fish. Aquat. Sci. 38:721-724

Strathmann RR (1967) Estimating the organic carbon content of phytoplankton from cell volume or plasma volume. Limnol. Oceanogr. 12:411-418

Strong DR (1992) Are trophic cascades all wet? Differentiation and donor-control in speciose ecosystems. Ecology 73:747-754

Tessier AJ, Consolatti NL (1991) Resource quantity and offspring quality in Daphnia. Ecology 72:468-478.

Thompson BM (1982) Growth and development of Pseudocalanus elongatus and Calanus sp. in the laboratory. J. Mar. Biol. Assoc. U.K. 62:359-372

Thompson RJ (1982) The relationship between food ration and reproductive effort in the green sea urchin, Strongylocentrotus droebachiensis. Oecologia 56:50-57

Twombly S (1993) Inter- and intrapopulational variation in time to metamorphosis in a freshwater copepod. Freshwater Biology 30:105-118

Twombly S (1995) Phenotypic variation in metamorphosis in four species of freshwater copepods. Freshwater Biology 34:29-38

Twombly S (1996) Timing of metamorphosis in a freshwater crustacean: comparison with anuran models. Ecology 77:1855-1866

Twombly S, Burns CW (1996) Exuvium analysis: a nondestructive method of analyzing copepod growth and development. Limnol. Oceanogr. 41:1324-1329

Twombly S, Burns CW (1996a) Effects of food quality on individual growth and development in 
the freshwater copepod Boeckella triarticulata. J. Plankton Res. 18:2179-2196

Twombly S, Clancy N, Burns CW (1998) Life history consequences of food quality in the freshwater copepod Boeckella triarticulata. Ecology 79:1711-1724

van den Bosch F, Gabriel W (1994) A model of growth and development in copepods. Limnol. Oceanogr. 39:1528-1542

van der Veer HW, Bergman MJN (1987) Predation by crustaceans on a newly settled 0-group plaice Pleuronectes platessa population in the western Wadden Sea. Mar. Ecol. Prog. Ser. 35:203-215.

Vidal J (1980) Physioecology of zooplankton. I. Effects of phytoplanton concentration, temperature, and body size on the growth rate of Calanus pacificus and Pseudocalanus sp. Mar. Biol. 56:111-134.

West TL, Costlow JD (1987) Size regulation in larvae of the crustacean Balanus eburneus (Cirripedia: Thoracica). Mar. Biol. 96:47-58

West TL, Costlow JD (1988) Determinants of the larval molting pattern of the crustacean Balanus eburneus Gould (Cirripedia: Thoracica). J. Exp. Zool. 248:33-44

Wilbur HM, Collins JP (1973) Ecological aspects of amphibian metamorphosis. Science 182:3051314

Zaret TM, Suffern JS (1976) Vertical migration in zooplankton as a predator avoidance mechanism. Limnol. Oceanogr. 21:804-813 
Table 1. Analysis of covariance for the effect of A. diet on the molt increment-size at molting relationship for Boeckella triarticulata ${ }_{2} \mathrm{n}=94$ for all relationships; B. diet (food concentration); and C. temperature on the relationship between molt increment and size at molting for Diaptomus leptopus. F value, level of statistical significance (p) and sample size (n) given for each stage

$\begin{array}{llll}\text { A. } & \text { Source } & \text { F value } & \mathbf{p} \\ \text { N2 size-N3 increment } & \text { Size } & 25.35 & 0.0001 \\ & \text { Diet } & 0.48 & 0.4888 \\ & \text { Diet*Size } & 0.42 & 0.517 \\ \text { N3 size-N4 increment } & \text { Size } & 21.08 & 0.0001 \\ & \text { Diet } & 1.07 & 0.303 \\ & \text { Size*Diet } & 1.16 & 0.284 \\ \text { N4 size-N5 increment } & \text { Size } & 88.98 & 0.0001 \\ & \text { Diet } & 0.67 & 0.416 \\ & \text { Size*Diet } & 0.59 & 0.445 \\ \text { N5 size-N6 increment } & \text { Size } & 39.51 & 0.0001 \\ & \text { Diet } & 0.03 & 0.866 \\ & \text { Size*Diet } & 0.01 & 0.929 \\ & \text { Size } & 56.51 & 0.0001 \\ \text { CI size-CII increment } & \text { Size } & 24.26 & 0.0001 \\ & \text { Diet } & 0.07 & 0.794 \\ & \text { Size*Diet } & 0.04 & 0.851 \\ & & \end{array}$




\begin{tabular}{|c|c|c|c|}
\hline & Diet & 0.11 & 0.735 \\
\hline & Size*Diet & 0.05 & 0.820 \\
\hline \multirow[t]{3}{*}{ CII size-CIII increment } & Size & 2.62 & 0.108 \\
\hline & Diet & 0.18 & 0.670 \\
\hline & Size*Diet & 0.10 & 0.752 \\
\hline \multirow[t]{3}{*}{ CIII size-CIV increment } & Size & 1.04 & 0.311 \\
\hline & Diet & 0.01 & 0.926 \\
\hline & Size*Diet & 0.01 & 0.913 \\
\hline \multicolumn{4}{|l|}{$\mathrm{CIV}$ size-CV increment } \\
\hline \multirow[t]{3}{*}{ females } & Size & 26.10 & 0.0001 \\
\hline & Diet & 1.70 & 0.199 \\
\hline & Size*Diet & 1.37 & 0.248 \\
\hline \multirow[t]{3}{*}{ males } & Size & 14.23 & 0.0005 \\
\hline & Diet & 0.66 & 0.421 \\
\hline & Size*Diet & 0.65 & 0.421 \\
\hline
\end{tabular}

CV size-CVI increment

$\begin{array}{llll}\text { females } & \text { Size } & 24.78 & 0.0001 \\ & \text { Diet } & 1.53 & 0.223 \\ & \text { Size*Diet } & 1.18 & 0.284 \\ \text { males } & \text { Size } & 4.90 & 0.032 \\ & \text { Diet } & 7.19 & 0.01\end{array}$


$\begin{array}{lll}\text { Size*Diet } \quad 6.72 & 0.013\end{array}$

B. $8^{\circ} \mathrm{C}$

Source F value

p

n

N6 size-CI increment

Food

4.66

0.033

82

Size

57.26

0.0001

Size*food

4.20

0.044

CI size- $\mathrm{CII}$ increment

Food

2.64

0.109

78

Size

9.63

0.003

Food*Size

2.60

0.111

CII size-CIII increment

Food

1.20

0.277

68

Size

70.21

0.0001

Food*Size

0.98

0.326

CIII size-CIV increment

Food

1.78

0.187

64

Size

11.71

0.0011

Food*Size

1.71

0.196

CIV size-CV increment

Food

0.15

0.695

64

CV size-CVI increment

Size

0.10

0.756

Food*Size

0.08

0.782

Food

1.26

0.263

64

Size

0.69

0.406 
$\begin{array}{lll}\text { Food*Size } \quad 1.22 & 0.271\end{array}$

$16^{\circ} \mathrm{C}$

N2 size-N3 increment

Food

1.84

0.182

52

Size

28.73

0.0001

Food*Size

1.64

0.206

N3 size-N4 increment

Food

0.97

0.328

58

Size

30.99

0.0001

Food*Size

0.95

0.334

N4 size-N5 increment

Food

0.09

0.765

57

Size

21.53

0.0001

Food*Size

0.09

0.763

N5 size-N6 increment

Food

2.14

0.149

57

Size

22.87

0.0001

Food*Size

1.96

0.168

N6 size-CI increment

Food

0.63

0.433

47

Size

54.53

0.0001

Food*Size

0.66

0.423

CI size-CII increment

Food

0.75

0.391

47

Size

9.44

0.004

Food*Size

0.72

0.400

CII size-CIII increment

Food

0.51

0.481

48 


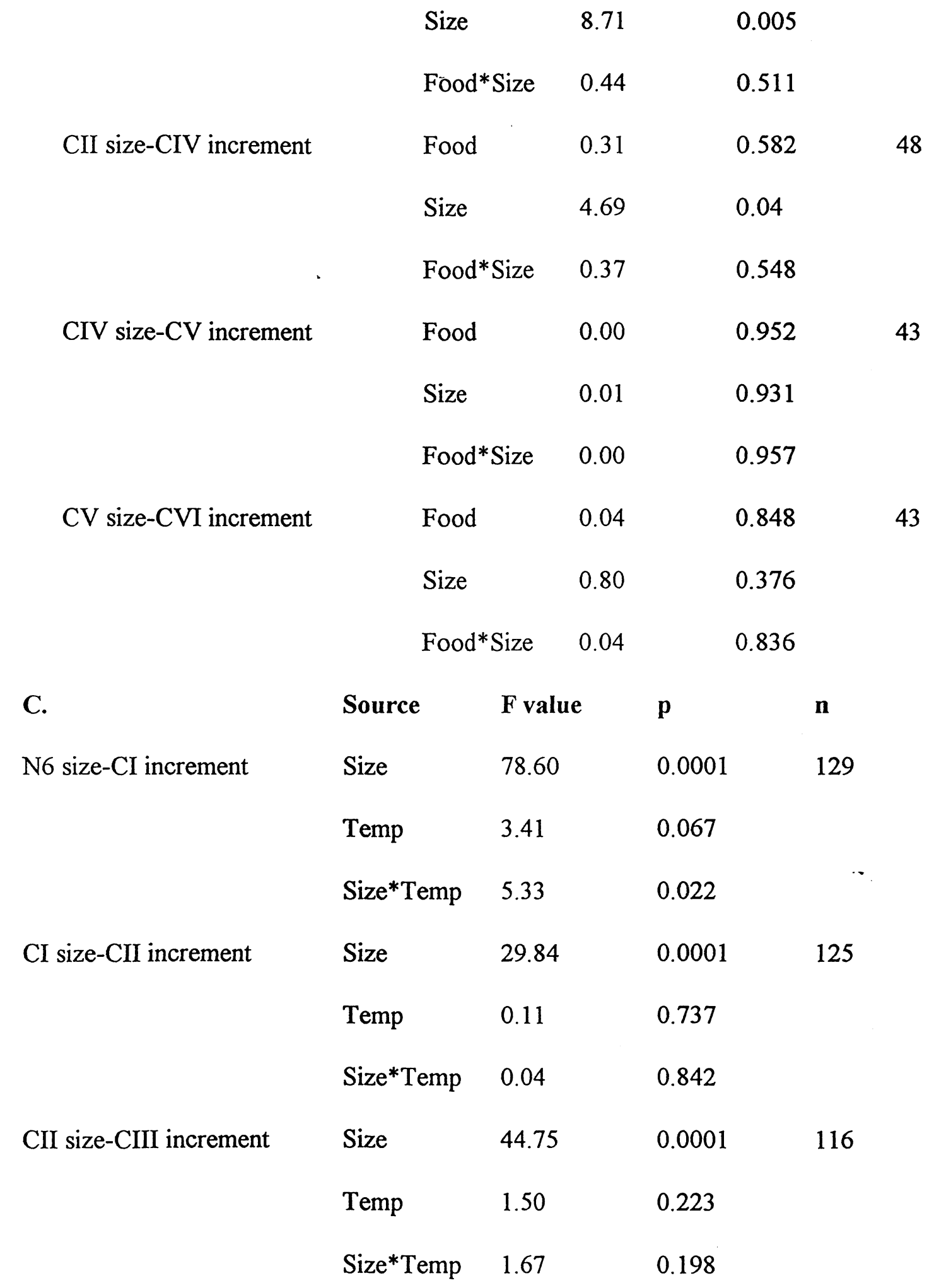




$\begin{array}{lllll}\text { CIII size-CIV increment } & \text { Size } & 16.80 & 0.0001 & 111 \\ & \text { Temp } & 0.59 & 0.445 & \\ & \text { Size*Temp } & 0.79 & 0.375 & \\ \text { CIV size-CV increment } & \text { Size } & 0.12 & 0.724 & 112 \\ & \text { Temp } & 0.02 & 0.901 & \\ & \text { Size*Temp } & 0.03 & 0.871 & \\ & \text { Size } & 8.25 & 0.005 & 117 \\ \text { CV size-CVI increment } & \text { Temp } & 0.58 & 0.449 & \\ & \text { Size*Temp } & 1.14 & 0.287 & \end{array}$




\section{Figure Captions}

Figure 1. Stage-specific body size and molt increment for A. Boeckella triarticulata, B. Diaptomus leptopus raised at $8^{\circ} \mathrm{C}$, and C. D. leptopus raised at $16^{\circ} \mathrm{C}$. Right-hand $\mathrm{Y}$-axis shows coefficients of variation for both traits. Asterisks indicate significant $(p<0.05)$ differences between individuals raised on different diets (food quality or quantity).

Figure 2. Stage-specific correlations of size at molting and molt increment for Boeckella triarticulata raised on Cryptomonas diet. Stage, Pearson product-moment correlation coefficients $\left(\mathrm{r}^{2}\right)$ and level of statistical significance (p) are shown for each cluster of points. Sample size $=47$ for all correlations.

Figure 3. As for Figure 2, for Diaptomus leptopus raised at $8^{\circ} \mathrm{C}$ in $\mathrm{A}$. low and B. high food concentrations. Sample sizes for each correlation: Low Food N6-CI=41, CI-CII=37, CII-CII=32, $\mathrm{CIII}-\mathrm{CIV}=32, \mathrm{CIV}-\mathrm{CV}=36, \mathrm{CV}-\mathrm{CVI}=37$; High Food N6-CI=41, CI-CII=41; CII-CIII=36, CIII$\mathrm{CIV}=32, \mathrm{CIV}-\mathrm{CV}=33, \mathrm{CV}-\mathrm{CVI}=37$. 
A
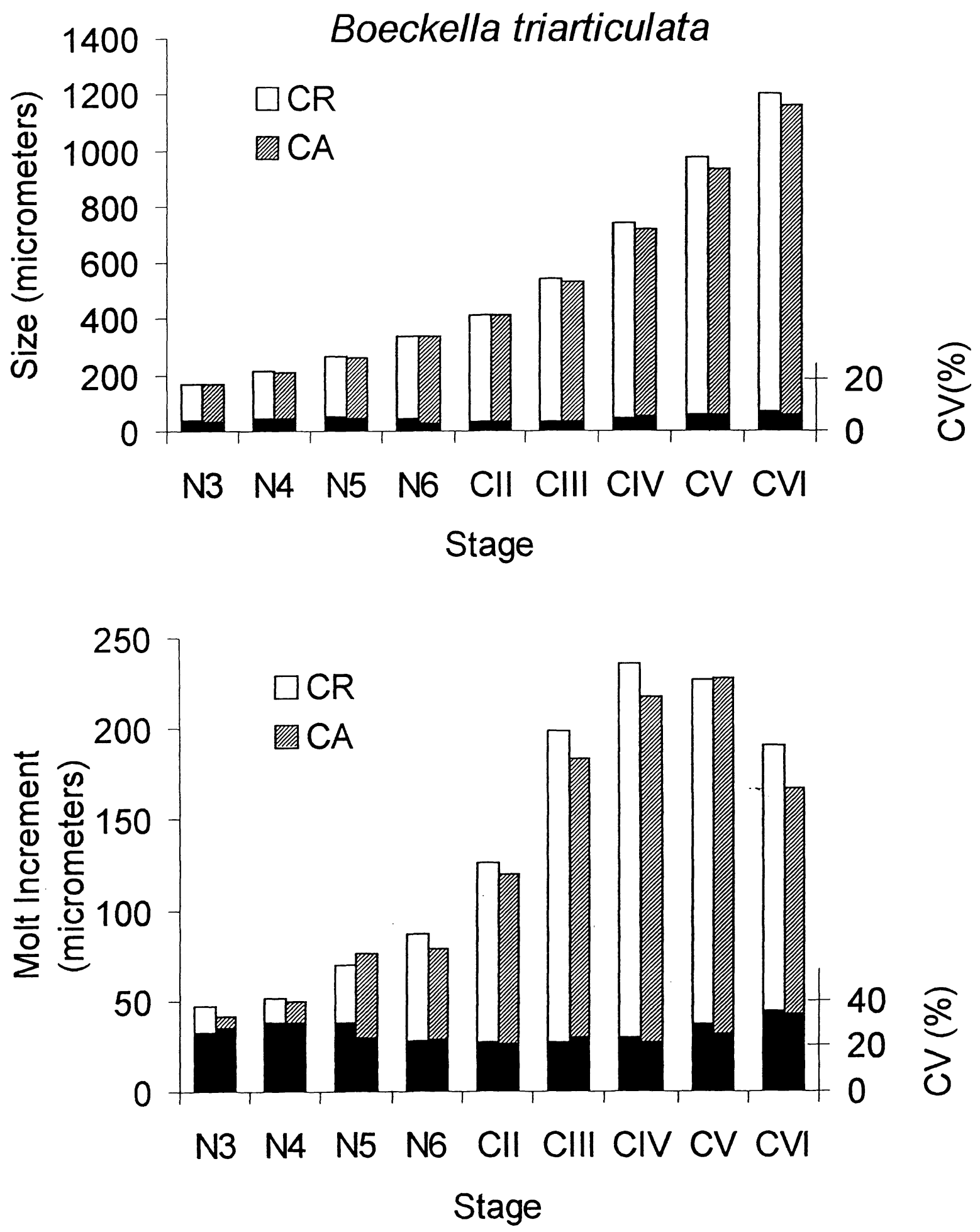

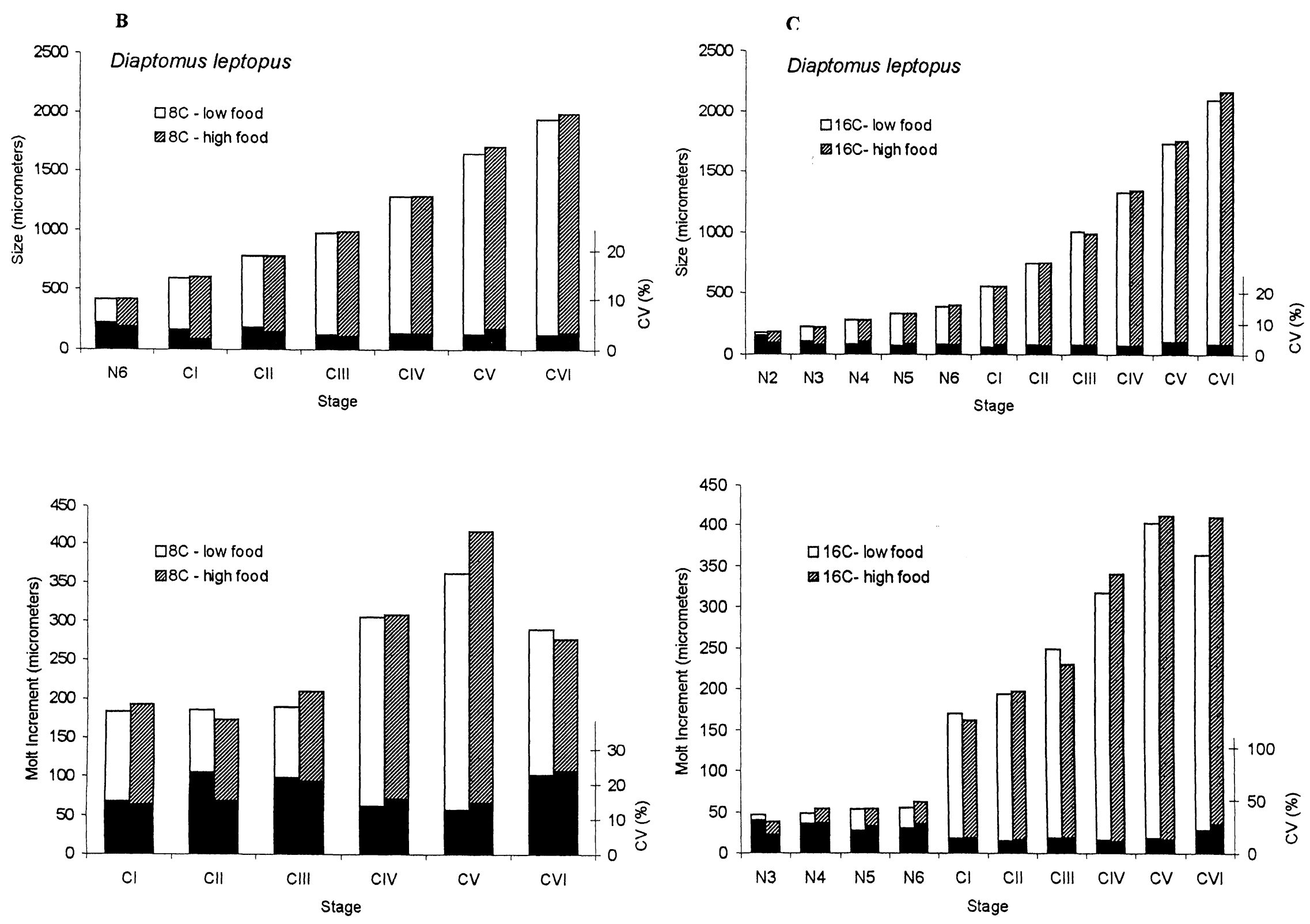

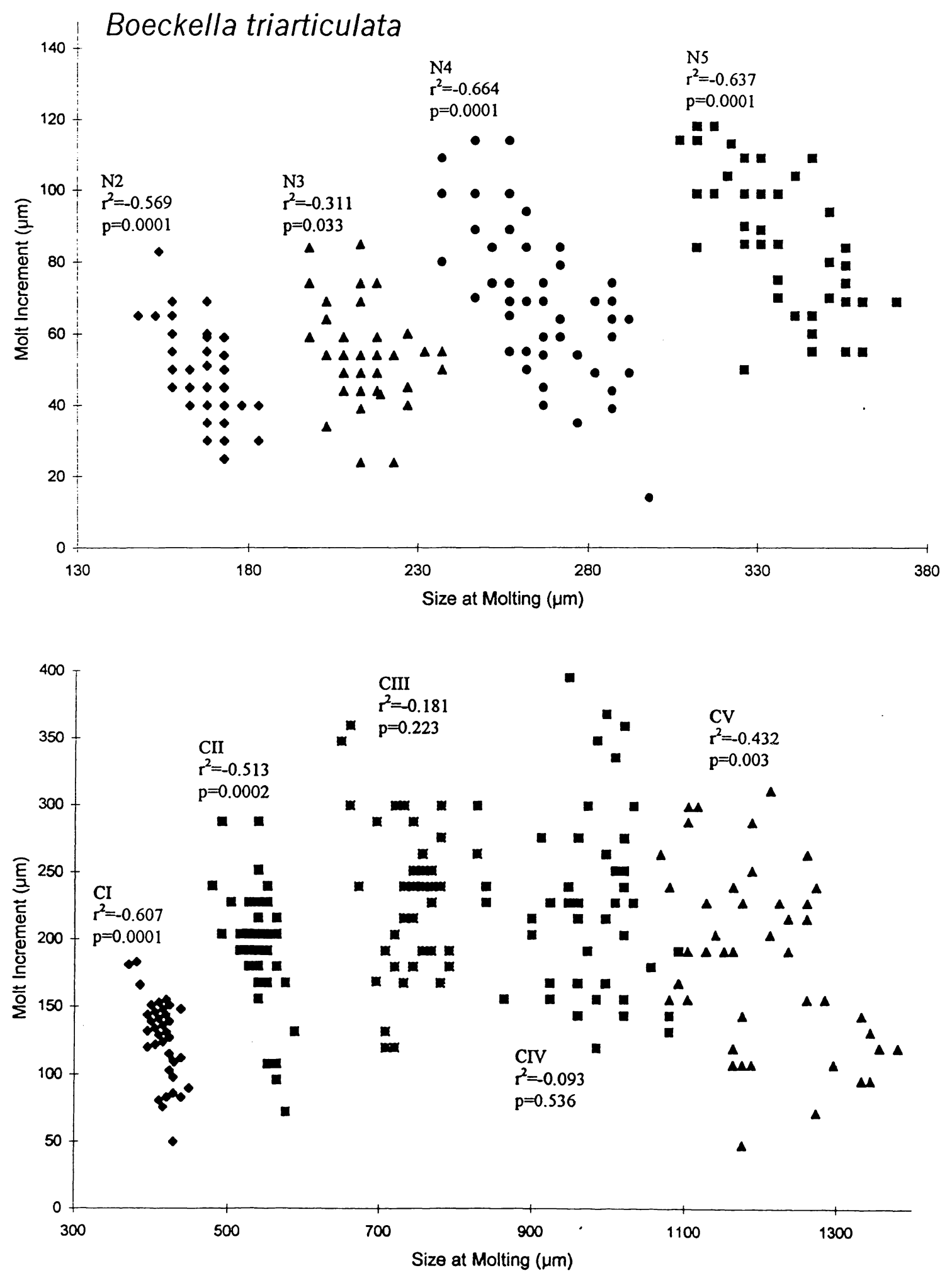

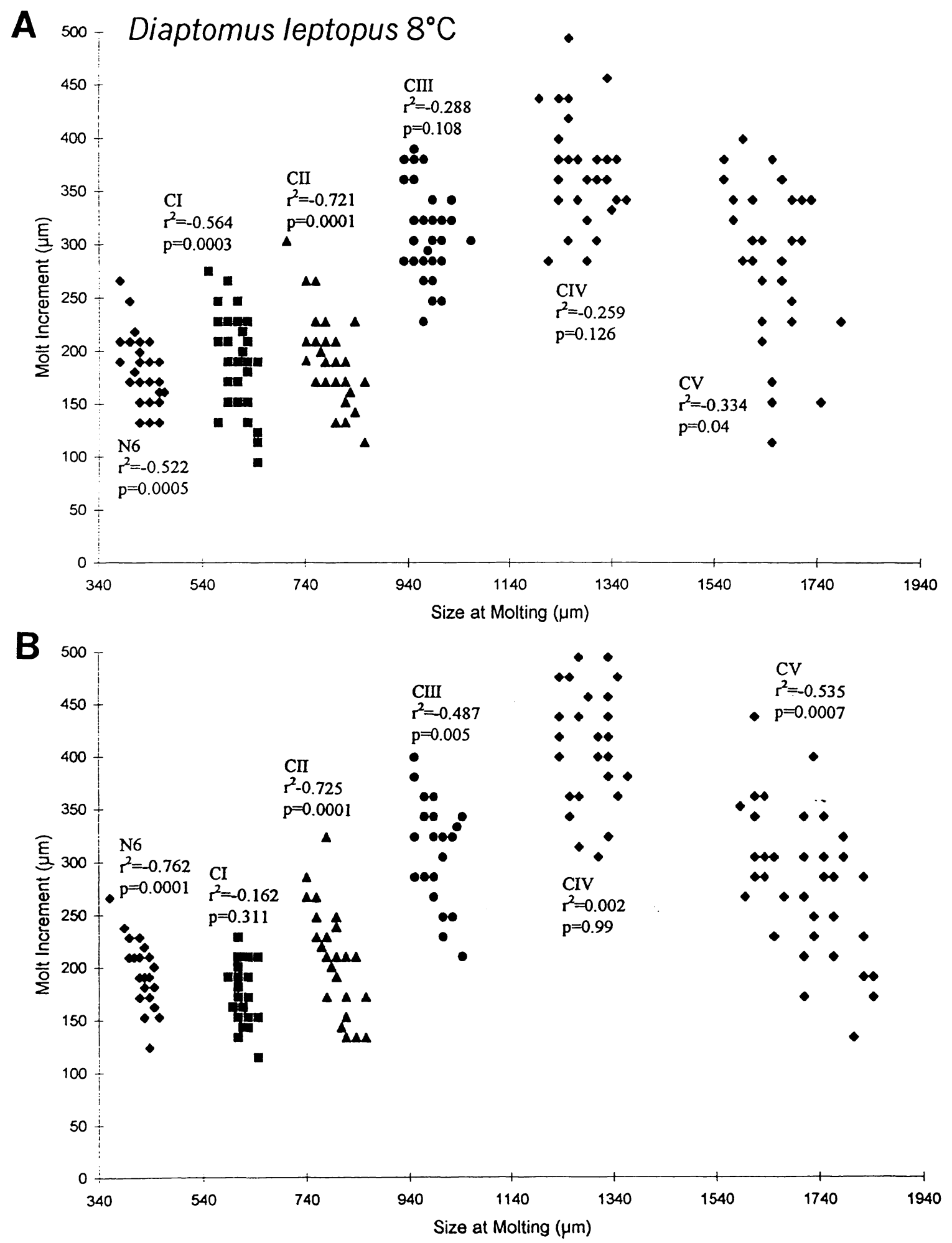